\section{The Effects of 3D Multi-User Virtual Environments on Collaborative Learning and Social Presence}

\author{
Hakan Tüzüna, ${ }^{a}$, Hatice Gökçe Bilgiç ${ }^{b}$, Sevil Yaşar Elçic
}

$\begin{array}{ll}\text { Received: } & 20 \text { December } 2018 \\ \text { Revised: } \quad & 05 \text { January } 2019 \\ \text { Accepted: } \quad & 15 \text { January } 2019 \\ \text { ISSN: 1307-9298 } \\ \text { Copyright @ IEJEE } \\ \text { www.iejee.com }\end{array}$

DOI: 10.26822/iejee.2019349247

\begin{abstract}
Three-dimensional Multi-User Virtual Environments (MUVEs) are being increasingly used in many areas, and they are becoming more and more integrated with learning and teaching. MUVEs can be used in learning and teaching to facilitate student learning and collaboration. This study identified the effects of MUVEs on collaborative learning and social presence and investigated whether these effects varied by gender. The participants were sophomore students attending a programming language course. They used a MUVE for their group meetings as part of their collaborative work. They also held voice communication. A four-section questionnaire was administered to the students who attended the meetings, in which the researchers served as facilitators. Interviews were held with randomly selected students. In addition, the group project meetings were tape-recorded, and field notes were taken for each meeting. The results showed that the MUVE enabled the group members to exchange ideas in an authentic environment, and that the file-sharing platform used as a complement to the MUVE reinforced collaborative learning. As long as technical problems are prevented, effective collaborative learning can be achieved in these environments.
\end{abstract}

Keywords: Artificial, Augmented, Virtual Realities, Collaborative Computing, Collaborative Learning, Distance Learnings

\section{Introduction}

Rapid advances in information and communication technologies have led to an increase in the use of three-dimensional Multi-User Virtual Environments (MUVEs) in many areas (Blas, Bucciero, Mainetti, \& Paolini, 2012) especially in the video game industry. In the meantime, changing students' needs and increasing use of technology in education lead educators to move on different technologies in educational area. During these developments, MUVEs are becoming more and more common in education as a new technology most specifically to create authentic learning environments (Doğan, Çınar, \& Tüzün, 2018). MUVEs are seen as an important technology to facilitate learning process if it is integrated into education within a well-designed educational context (Blas et al., 2012). Especially, the academic world and educators has been quite interested in the use of MUVEs (Dickey, 2000; Doğan, Çınar, \& Tüzün, 2018; Messinger et al., 2009; Poppe, Brown, Recker, Johnson, \& Vanderfeesten, 2017) since their future of being effective in remote collaborative learning environments due to their immersion, interaction and communication capabilities (Ibanez, Rueda, Maroto, \& Kloos, 2013). According to the 2007 Horizon Report, three-dimensional environments can potentially be used in future educational processes, and developments in open sources and standards will bring MUVEs closer and closer to formal educational methods with each passing year (EDU-CAUSE, 2007).

MUVEs are defined as persistent and dynamic simulated three-dimensional environments that are characterized by rich graphics, high-quality sound, motion, perspective, and interaction (Schultze \& Orlikowski, 2010). Virtual environments are three-dimensional environments in which people can move around using avatars, interact with others, manipulate objects, and get information (Sallnas, 2005). The design of modern virtual environments has been predominantly pseudo-realistic. This is not a photorealistic design, but a de- sign in which designers assemble components from the real world (McCreery, Schrader, Krach, \& Boone, 2013). Originally introduced as video game environments, virtual worlds have received wide currency in the business world and educational settings in the form of project management, online learning, and simulations (Schultze \& Orlikowski, 2010). Educational MUVEs combine two-dimensional and three-dimensional virtual worlds in which users are represented by avatars (Cobb, Neale, Crosier, \& Wilson, 2002; Nelson, Ketelhut, Clarke, Bowman, \& Dede, 2005). Using avatars provide users to explore three-dimensional worlds, to interact with objects, to communicate with other users, and to participate in collaborative activities. Each virtual world has its own visual theme, mechanisms, and intra-world activity groups. A common practice in most MUVEs is collaborative activities (Annetta \& Park, 2006; Bruckman, 1996; Bruckman, 2000; Clarke, Dede, Ketelhut, \& Nelson, 2006; Corbit, 2002; Dickey, 2000; Dickey, 2003; Nelson et al., 2005). In some studies, virtual environments defined as Collaborative Virtual Environments (CVEs) in which users can share virtual objects, communicate and work together through 3D spaces (Chellali, Milleville-Pennel, \& Dumas, 2013; Poppe et al., 2017).

Social presence concerns the realism of these environments. It refers to the extent to which people are significant in their interpersonal interactions. Social presence theory is used to determine whether an environment can enable its users to feel that they are physically present in an environment. Using face-to-face communication as a standard, social presence relies not only on words, but also on non-verbal body language and content (Rice, 1992). Research on online discussion environments suggests that technological media has the ability to generate the feeling of presence (Bosch-Sijtsema \& Haapamaki, 2014; Gunawardena \& Zittle, 1997; Leh, 2001; Poole, 2000; Rourke, Andersın, Garrison, \& Archer, 2001). Especially, virtual environments' capability of producing a sense of presence is underlined in literature (Davis, Murphy, 
Owens, Khazanchi, \& Zigurs, 2009; Zhao, 2003). Avatars are seen as the most effective tool in virtual environments to provide social presence (Bosch-Sijtsema \& Haapamaki, 2014; Davis et al., 2009; Zhao, 2003).

Project-based collaborative work has been used intensively in both business and education. In addition, there are more and more people who attend online distance learning programs. Therefore, studies have focused on how project groups should meet and solve problems associated with their collaborative work. The distance between users is a significant factor in this respect. In collaborative work, it is likely that physical distance between users will negatively affect productivity. Swan (2003) asserted that educational activities should be restructured in a way to reduce the psychological and emotional problems brought on by distance. This is because, as stated by Salmon (2004), collaboration is only possible when users feel at ease and are provided with the opportunity for online socialization. MUVEs have different features that provide project members to interact with avatars and enable distant team members to collaborate in project studies. Thus, sense of presence and social interaction option through MUVEs can provide a sense of shared space among the distributed team members which can affect the group performance positively (Bosch-Sijtsema \& Haapamaki, 2014).

Many researchers have reported that the distinctive interactive processes of collaborative learning offer many advantages (Hämäläinen, Manninen, Järvelä, \& Häkkinen, 2006). Moreover, it is important to provide sharing and developing new ideas among the distributed team members in collaborative team studies (Bosch-Sijtsema \& Haapamaki, 2014). MUVEs can be alternative ways to provide communication and collaboration among team members especially in distant team members. A review of the literature indicates that there are many studies on the use of information and communication technologies for educational purposes. However, few focus on the effectiveness of the use of three-dimensional MUVEs for group projects. There is limited research on the use of MUVEs, which are developed mainly for recreational purposes, for collaborative learning (Edirisingha, Nie, Pluciennik, \& Young, 2009). This study had students collaborate on a project in a three-dimensional MUVE to determine the effectiveness of the environment.

\section{Research Question}

The research question was: "What are the effects of three-dimensional Multi-User Virtual Environments on university students' collaborative learning and social presence during collaborative work on a group project?"

\section{Methodology}

This is a mixed-method study, using both quantitative and qualitative research methods. Adopting an ethnographic approach, a form of qualitative research, the researchers participated in project group work in the three-dimensional multi-user virtual learning environment and observed the procedures. Then, they held interviews with the participants. Finally, a questionnaire was administered to the participants to collect quantitative data.

\section{Research Context and Participants}

The participants were composed of sophomore students attending the course, Programming Languages II, as part of the curriculum of the Department of Computer Education and Instructional Technology at a large state university in Ankara, Turkey. Purposive sampling was used to select 35 students to meet regularly for collaborative work on a group project.

While $33 \%$ of the participants were female, $67 \%$ were male. More than half of them (60\%) were intermediate computer users, and $40 \%$ were advanced. Only $40 \%$ of the participants had experience with MUVEs, and only $3 \%$ had an experience with collaborative learning activity in such an environment.

\section{Procedures}

This study used Active Worlds, an online three-dimensional multi-user virtual environment, which was developed to host many virtual worlds. Users can move around these virtual worlds using their accounts. They are represented by customized avatars. They can use written and voice communication (through VolP). In addition, Dropbox was used as a file sharing environment to supplement the three-dimensional multi-user virtual environment.

Before the study, the researchers held test meetings in Active Worlds, during which they tested both written and voice communication. They created usernames and passwords for the participants. They discussed which application they would use for the meetings and worked on the design of the environment. Of the researchers, one facilitator was assigned to each project group. In addition, a meeting room was created on Active Worlds for each project group. Each meeting room included photographs of the students and the facilitator, which were linked to the personal webpages designed by the participants to introduce themselves. A four-week period was scheduled for the meetings, and the plan was to have at least one meeting per week with each group. Before the meetings, the students were informed by the instructor about the process and given "Principles about the Facilitators," a document prepared by the researchers and the instructor. The document described the relationships between the students and their facilitators as well as the duties of the latter. The researchers who would serve as facilitators cooperated with the instructor to collect information about their project group. Finally, the facilitators sent e-mails to the students in their groups to introduce themselves briefly and give them their usernames and passwords.

During the study, the facilitators held group project meetings in the MUVE with the project groups. Figure 1 shows a sample screenshot of a meeting. During the meetings, the facilitators observed student activities and the usability of the environment. As facilitators, the researchers checked on the students' work once or twice a week for four weeks and took field notes after each meeting.

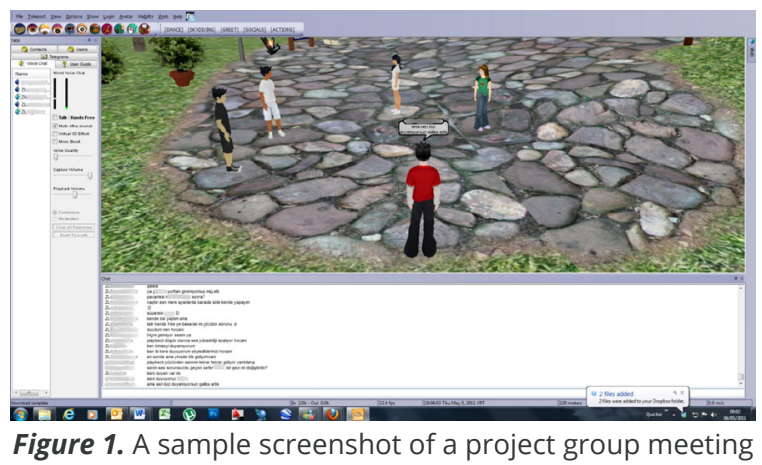

Figure 1. A sample screenshot of a project group meeting in active worlds

After four weeks of meetings in the MUVE, the Collaborative Learning, Social Presence and Satisfaction Questionnaire was administered to 30 students who had 
participated in at least one of the meetings. In addition, semi-structured interviews were held with 12 students, three randomly selected students from each group. Depending on availability, these interviews took place either face-to-face or on the Internet. With the students' consent, the meetings were tape-recorded and transcribed.

\section{Data Sources}

The Collaborative Learning, Social Presence and Satisfaction Questionnaire, developed by So and Brush (2008), was adapted to the context of the three-dimensional MUVE. The qualitative data were collected through semi-structured interviews with questions created by the researchers. Field notes by the researchers were used as qualitative observation data.

\section{The collaborative learning, social presence and satisfaction questionnaire}

This questionnaire has four sections: demographics, collaborative learning, social presence, and satisfaction. The first section contains questions about the participants gender and age as well as their experience with computers, MUVEs, and collaborative learning in a MUVE. The second section, which addresses collaborative learning, has 8 items, which were adapted to this research. The third section on social presence originally had 17 items. For this study, 5 items were excluded as inconsistent with the purpose of the study, resulting with 12 items. The 11 items in the last section, which attempts to measure the level of student satisfaction, were adapted and then used. The questionnaire thus had 36 items, 5 in the sub-dimension of demographics and 31 items in the sub-dimensions of collaborative learning, social presence, and satisfaction. The questionnaire uses a five-point Likert-type scale with these options: "Strongly Disagree," "Disagree," "Neutral," "Agree," and "Strongly Agree." The questionnaire was revised after consultation with two instructional technology specialists.

\section{The semi-structured interview form}

In accordance with the purpose of this study, the researchers developed a semi-structured interview form to collect information about the students' experience with the MUVE, its usability, and its contributions to communication, as well as about the effectiveness of the group projects and sharing. The form consisted of 12 questions in two sections. The first section asked questions about the MUVE, and the second section asked about the group activities during virtual meetings. The form was revised in accordance with the opinions of two instructional technology specialists.

\section{Field notes and tape recordings}

The researchers attended the meetings in the MUVE as facilitators. For each meeting, they took field notes to record their observations. Some meetings were tape-recorded in the form of streaming video. In the end, there were 28 pieces of field notes, one for each meeting.

\section{Data Analysis}

The data analysis involved the data from the questionnaire, the field notes, and the observation data. This study used triangulation, which is a widely recommended method for ensuring reliability in qualitative research (Denzin, 1970; Denzin, 1978; Patton, 1999). All three components of triangulation were used: (1) multiple data collection methods, (2) multiple researchers, and (3) multiple sources of data. This study's multiple data collection methods were observation, the field notes, and the questionnaire. The transcripts of the interviews were coded by more than one researcher, which ensured that multiple researchers were involved in data analysis.

The field notes and interviews, the study's qualitative data, were subject to content analysis and themes were generated. The analysis of the data from the questionnaire, the study's quantitative data, involved frequencies, distribution of percentages, and an independent t-test. The level of significance for statistical analysis was 0.05 .

\section{Findings}

The findings are presented under three headings: data from the questionnaire, field notes and interviews.

\section{Data from the Questionnaire}

\section{Collaborative learning}

The participants reported that their experience with collaborative learning in the MUVE was not better than faceto-face collaborative learning. In addition, most were neu-

Table 1. Collaborative Learning in the MUVE

\begin{tabular}{|c|c|c|c|c|c|c|c|c|c|c|c|}
\hline & \multirow{3}{*}{ Collaborative Learning Dimension } & \multicolumn{10}{|c|}{ Collaborative Learning in 3D MUVE } \\
\hline & & \multicolumn{2}{|c|}{$\begin{array}{l}\text { Strongly } \\
\text { Disagree }\end{array}$} & \multicolumn{2}{|c|}{ Disagreee } & \multicolumn{2}{|c|}{ Neutral } & \multicolumn{2}{|c|}{ Agree } & \multicolumn{2}{|c|}{$\begin{array}{l}\text { Strongly } \\
\text { Agree }\end{array}$} \\
\hline & & $f$ & $\%$ & $f$ & $\%$ & $f$ & $\%$ & $f$ & $\%$ & $f$ & $\%$ \\
\hline 1 & $\begin{array}{c}\text { Collaborative learning environment in 3D MUVE is better } \\
\text { than in a face-to-face learning environment. }\end{array}$ & 14 & 47 & 10 & 33 & 3 & 10 & 3 & 10 & 0 & 0 \\
\hline 2 & $\begin{array}{c}\text { Overall, I am satisfied with my collaborative learning } \\
\text { experience in this course. }\end{array}$ & 3 & 10 & 7 & 23 & 14 & 47 & 6 & 20 & 0 & 0 \\
\hline 3 & Collaborative learning in my group is effective. & 2 & 7 & 14 & 47 & 8 & 27 & 6 & 20 & 0 & 0 \\
\hline 4 & $\begin{array}{l}\text { I was able to develop problem solving skills through } \\
\text { peer collaboration in 3D MUVE. }\end{array}$ & 4 & 13 & 14 & 47 & 8 & 27 & 4 & 13 & 0 & 0 \\
\hline 5 & Collaborative learning in my group was time-consuming. & 1 & 3 & 8 & 27 & 4 & 13 & 7 & 23 & 10 & 33 \\
\hline 6 & I felt part of a learning community in my group. & 1 & 3 & 8 & 27 & 10 & 33 & 11 & 37 & 1 & 3 \\
\hline 7 & $\begin{array}{l}\text { I actively engaged my ideas with group members in 3D } \\
\text { MUVE. }\end{array}$ & 3 & 10 & 10 & 33 & 5 & 17 & 11 & 37 & 1 & 3 \\
\hline 8 & $\begin{array}{l}\text { I was able to develop new skills and knowledge from } \\
\text { other members in my group study in 3D MUVE. }\end{array}$ & 7 & 23 & 6 & 20 & 8 & 27 & 8 & 27 & 1 & 3 \\
\hline
\end{tabular}


Table 2. Social Presence in 3D MUVE

\begin{tabular}{|c|c|c|c|c|c|c|c|c|c|c|c|}
\hline & \multirow{3}{*}{ Social Presence Dimension } & \multicolumn{10}{|c|}{ Social Presence in 3D MUVE } \\
\hline & & \multicolumn{2}{|c|}{$\begin{array}{l}\text { Strongly } \\
\text { Disagree }\end{array}$} & \multicolumn{2}{|c|}{ Disagreee } & \multicolumn{2}{|c|}{ Neutral } & \multicolumn{2}{|c|}{ Agree } & \multicolumn{2}{|c|}{$\begin{array}{l}\text { Strongly } \\
\text { Agree }\end{array}$} \\
\hline & & $f$ & $\%$ & $f$ & $\%$ & $f$ & $\%$ & $f$ & $\%$ & $f$ & $\%$ \\
\hline 1 & $\begin{array}{c}\text { Using 3D MUVE is a pleasant way to communicate with } \\
\text { others. }\end{array}$ & 5 & 10 & 4 & 13 & 6 & 20 & 10 & 33 & 5 & 17 \\
\hline 2 & $\begin{array}{l}\text { The language people use to express themselves in } \\
\text { online communication is stimulating. }\end{array}$ & 5 & 17 & 6 & 20 & 9 & 30 & 10 & 33 & 0 & 0 \\
\hline 3 & $\begin{array}{c}\text { It is easy to Express what I want to communicate } \\
\text { through 3D MUVE. }\end{array}$ & 6 & 20 & 7 & 23 & 5 & 17 & 9 & 30 & 3 & 10 \\
\hline 4 & $\begin{array}{l}\text { The language used to Express oneself in online } \\
\text { communication is easily understood. }\end{array}$ & 4 & 13 & 9 & 30 & 6 & 20 & 10 & 33 & 1 & 3 \\
\hline 5 & $\begin{array}{l}\text { I am comfortable participating, even though I am not } \\
\text { familiar with the topics }\end{array}$ & 5 & 17 & 8 & 27 & 4 & 13 & 11 & 37 & 2 & 7 \\
\hline 6 & 3D MUVE is technically reliable. & 3 & 10 & 3 & 10 & 9 & 30 & 13 & 43 & 2 & 7 \\
\hline 7 & $\begin{array}{l}\text { 3D MUVE allow relationships to be established based } \\
\text { upon sharing and exchanging information. }\end{array}$ & 4 & 13 & 4 & 13 & 10 & 33 & 12 & 40 & 0 & 0 \\
\hline 8 & $\begin{array}{l}\text { 3D MUVE allows me to build more caring social rela- } \\
\text { tionship with others. }\end{array}$ & 6 & 20 & 11 & 37 & 5 & 17 & 7 & 23 & 1 & 3 \\
\hline 9 & $\begin{array}{l}\text { It is unlikely that someone might obtain personal } \\
\text { information about you from the 3D MUVE messages. }\end{array}$ & 2 & 7 & 9 & 30 & 11 & 37 & 6 & 20 & 2 & 7 \\
\hline 10 & $\begin{array}{c}\text { Where I access 3D MUVE (home, office, computer labs, } \\
\text { public areas, etc.) does not affect my ability/desire to } \\
\text { participate. }\end{array}$ & 9 & 30 & 9 & 30 & 3 & 10 & 7 & 23 & 2 & 7 \\
\hline 11 & 3D MUVE permits the building of trust relationships. & 6 & 20 & 6 & 20 & 5 & 17 & 13 & 43 & 0 & 0 \\
\hline 12 & $\begin{array}{l}\text { The large amounts of participants in 3D MUVE (num- } \\
\text { bers of participants and frequency of dialogs) do not } \\
\text { inhibit my ability to communicate. }\end{array}$ & 7 & 23 & 3 & 10 & 4 & 13 & 12 & 40 & 4 & 13 \\
\hline
\end{tabular}

tral about their level of satisfaction with the experience. Moreover, the dissatisfied participants outnumbered those who were satisfied. Slightly less than half of the participants (47\%) described their level of satisfaction as "neutral," and 33\% reported their dissatisfaction. Only $20 \%$ reported that they were satisfied (Table 1 ). Furthermore, the participants did not agree with the idea that their problem-solving skills were developed through collaborative learning in the MUVE, nor did they think that collaborative learning in their group was effective. More than half of the participants (54\%) said that the activities in the MUVE were not effective collaborative learning, and $56 \%$ reported that collaborative learning in the MUVE was time-consuming (Table 1).

\section{Social Presence}

The participants reported that using the MUVE was a pleasant way to communicate with others, and that the MUVE was technically reliable. Half of the participants said that using the MUVE was a pleasant way to communicate with others. In addition, 40\% said that the MUVE allowed relationships to be established based on sharing and exchanging information. However, $57 \%$ of them disagreed with the idea that the MUVE helped them establish social bonds with their group (Table 2)

\section{Satisfaction}

It was found that the participants learned from their experiences in the MUVE, these experiences were useful, the activities assisted them in understanding other points of view, the facilitators met their expectations, and the diversity of the meetings helped them to express their opinions in the discussions. Even so, the MUVE did not fully meet their expectations or stimulate them to do additional research or activities.
Two-fifths of the participants reported that the activities in the MUVE were useful experiences. In addition, half of them said that the meetings in the MUVE helped them to express their opinions in the discussions. Nevertheless, the MUVE did not fully meet the expectations of $44 \%$ of the participants (Table 3).

The results of the questionnaire were also analyzed by gender. The questionnaire forms were filled out by 30 participants (10 female and 20 male). The mean scores of the female and male participants in collaborative learning were 20.4 and 22.5 , respectively. In other words, male participants had a slightly higher mean score in collaborative learning.

The mean scores of female and male participants in social presence were 30.4 and 36.9 , respectively. The males had a higher mean score in social presence. The mean scores of female and male participants in satisfaction were 29 and 34.4, respectively. Again, the males had a higher mean score in satisfaction. The results of the t-test showed that the difference between the genders was only significant in the sub-dimension of satisfaction $(t(28)=-2.13, p=.042)$.

\section{Field Notes}

Content analysis of the researchers' field notes yielded six categories.

\section{The role of the facilitators}

The need for guidance prevailed in the learning process in the MUVE. To meet this need, a facilitator was assigned to each group. The guidance of the facilitators helped to smoothly organize the project. In particular, their guidance focused on three issues: (1) problems with the group work, (2) instructions for using the environment (e.g. the 
Table 3. Satisfaction in 3D MUVE

\begin{tabular}{|c|c|c|c|c|c|c|c|c|c|c|c|}
\hline & \multirow{3}{*}{ Satisfaction Dimension } & \multicolumn{10}{|c|}{ Satisfaction in 3D MUVE } \\
\hline & & \multicolumn{2}{|c|}{$\begin{array}{l}\text { Strongly } \\
\text { Disagree }\end{array}$} & \multicolumn{2}{|c|}{ Disagreee } & \multicolumn{2}{|c|}{ Neutral } & \multicolumn{2}{|c|}{ Agree } & \multicolumn{2}{|c|}{$\begin{array}{l}\text { Strongly } \\
\text { Agree }\end{array}$} \\
\hline & & $f$ & $\%$ & $f$ & $\%$ & $f$ & $\%$ & $f$ & $\%$ & $f$ & $\%$ \\
\hline 1 & $\begin{array}{l}\text { I was able to learn new things while studying in 3D } \\
\text { MUVE. }\end{array}$ & 2 & 7 & 6 & 20 & 10 & 33 & 12 & 40 & 0 & 0 \\
\hline 2 & $\begin{array}{l}\text { I was stimulated to do additional Research and } \\
\text { study on topics discussed in 3D MUVE. }\end{array}$ & 4 & 13 & 9 & 30 & 11 & 37 & 6 & 20 & 0 & 0 \\
\hline 3 & $\begin{array}{l}\text { Discussions in 3D MUVE assisted me in } \\
\text { understanding other points of view. }\end{array}$ & 2 & 7 & 4 & 13 & 10 & 33 & 13 & 43 & 0 & 0 \\
\hline 4 & $\begin{array}{c}\text { As a result of my experience in 3D MUVE, I would } \\
\text { like to attend another similar 3D MUVE } \\
\text { experience in the future. }\end{array}$ & 3 & 10 & 9 & 30 & 5 & 17 & 11 & 37 & 2 & 7 \\
\hline 5 & Studying in 3D MUVE was a useful experience. & 2 & 7 & 7 & 23 & 8 & 27 & 13 & 43 & 0 & 0 \\
\hline 6 & $\begin{array}{l}\text { The diversity of meetings in 3D MUVE prompted me } \\
\text { to participate in the discussions. }\end{array}$ & 1 & 3 & 5 & 17 & 9 & 30 & 13 & 43 & 2 & 7 \\
\hline 7 & $\begin{array}{l}\text { I put in a great deal of effort to participate the } \\
\text { studies and discussions in 3D MUVE. }\end{array}$ & 2 & 6.7 & 11 & 36.7 & 3 & 10 & 5 & 16.7 & 9 & 30 \\
\hline 8 & $\begin{array}{l}\text { My level of learning that took place in 3D MUVE was } \\
\text { of the highest quality. }\end{array}$ & 9 & 30 & 7 & 23.3 & 7 & 23.3 & 5 & 16.7 & 2 & 6.7 \\
\hline 9 & $\begin{array}{l}\text { Overall, the activities (group work) in 3D MUVE met } \\
\text { my expectations. }\end{array}$ & 6 & 20 & 13 & 43 & 7 & 23 & 4 & 13 & 0 & 0 \\
\hline 10 & $\begin{array}{l}\text { Overall, the team coach in 3D MUVE met my } \\
\text { expectations. }\end{array}$ & 1 & 3 & 3 & 10 & 8 & 27 & 15 & 50 & 3 & 10 \\
\hline 11 & Overall, 3D MUVE met my expectations. & 5 & 17 & 8 & 27 & 9 & 30 & 8 & 27 & 0 & 0 \\
\hline
\end{tabular}

location of the meeting rooms, how to activate sound, how to deal with technical problems and so forth) and (3) the management of collaborative group work. Half of the participants reported in the questionnaire that the facilitators met their expectations, which suggests that their presence in the environment was useful.

\section{The usability of the environment}

A look at the profiles of the participants indicates that $60 \%$ of them were intermediate computers users and $40 \%$ had experience with MUVEs. Some participants were completely at ease with using the environment during the meetings. However, others did need instructions. Four aspects of the environment's usability were analyzed: moving around with the avatars, going anywhere in the environment by following instructions, using the menus, and customizing the avatars. The students did not have difficulty moving around the environment, and a large majority of them were able to arrive at the meeting rooms by following the instructions. However, some participants needed instructions to use the menus. In addition, some participants reported that it would have been better if they had been informed by the facilitators about how to use the menus. Most of the participants did not customize their avatars. Some who noticed this feature were unable to customize their avatars because they could not figure out how to do so.

\section{Technical Problems}

There were several technical problems with the MUVE during group work. These problems were generally associated with the software, the participants' equipment, and poor Internet connections. The problem with the software was that the participants were frequently disconnected from the environment. This happened whenever the participants logged in to the environment. Another problem with the software was related to sound control during voice communication. When a connection prob- lem occurred, the software reactivated the sound of those participants who had been muted. This made it necessary to mute them again and again, making the meeting process ineffective. The problems with equipment involved malfunctioning microphones or the lack of microphones, which made voice communication impossible. Finally, the process was hindered by the physical environment where the participants connected to the Internet, the capacity of the network that they were using, and connection speed. For example, some participants had to use written communication as an alternative to voice communication since their speech was occasionally interrupted because of a slow connection. This was especially the case for participants who were connecting to the Internet in dormitories, where the connections were slow because of network congestion. Some participants chose not to use voice communication in order not to disrupt others since they were connecting to the Internet at a library.

\section{Communication and Interaction}

In a virtual environment, written and voice communication should be trouble-free so that they can substitute for physical meetings. However, the success of communication, one of the crucial factors in the effectiveness of collaborative learning in a virtual environment, was not uniform in Active Worlds. Written communication was mostly trouble-free, but this was not the case for voice communication. The reasons for the malfunction in voice communication were technical problems with the software, Internet connections, and the participants' equipment. For example, one technical problem with the software was that some participants, who could hear others and speak to them in their previous logins, were unable to use hearing and speaking functions properly even though they had not modified their equipment or Internet connection. This problem, which occurred on several occasions and in a variety of forms, could not be overcome by the participants, and instructions from the facilitators were ineffective most of the time. In addition, some participants failed to 
use voice communication in the MUVE even though they could effectively use it in other environments, suggesting another technical problem associated with the software. Unlike the problems with the software, the problems with Internet connections and equipment were mostly overcome thanks to instructions from the facilitators or the individual efforts of the participants.

\section{Collaborative Work}

The MUVE was used to enable the groups to work in a collaborative learning environment. The participants usually collaborated to exchange ideas, shared the links to the materials and videos they had found and received instant feedback. Furthermore, the group members assigned tasks and checked each other's tasks, warning one another when necessary. In addition to the MUVE, Dropbox was also used for sharing files. The group members instantly revised their files in Dropbox in accordance with their discussions in the MUVE. In other words, they instantly put their ideas into practice in collaboration with the other group members. Using the MUVE and Dropbox together ensured that group work was based on collaboration. With its features of written and voice communication, the MUVE was used for collaborative learning, while Dropbox was used for sharing.

\section{Meeting Location}

A specific meeting location was assigned to each group, and all members were asked to be in that room at the time of the meeting. For each group, the photographs of the members and their facilitator were included in the design of the meeting room. The field notes indicate that the group members participated in some of the meetings by positioning themselves under their own photographs. In addition, some students warned others to position themselves under their photographs, and there were some discussions about why it was necessary to do so. In other words, some students concluded from the presence of photographs that all participants had to position themselves under their own photographs, whereas others did not. This type of positioning was common among female participants, while the male participants did not follow this practice.

\section{Interviews}

The interviews with the participants of the group project meetings in the MUVE generated 11 categories.

\section{Avatars}

Most of the participants did not customize the appearance of their avatars by modifying their clothing or hair. Only a quarter of the participants customized their avatars. Generally, they did so to stand out or to create a sense of belonging:

Participant 6: "I changed the physical appearance of my avatar to create my own style."

Participant 8: "It helped me to express myself better."

Participant 9: "I did so to stand out among others. It also helped me to have a sense of belonging."

The reasons why the avatars were not customized were because the participants did not notice this feature, could not figure out how to do so or did not want to waste their time:

Participant 11: "I did not notice it at all. I guess I did not feel the need."
Participant 2: "I did not customize my avatar. This is because I did not know how to do so, and I did not care that much."

Participant 12: "I noticed this feature, but I was not interested. I found it unnecessary and did not want to waste my time."

Most participants reported that being represented by an avatar made the environment more authentic and created the feeling of togetherness:

Participant 7: "We were able to communicate in an environment which was almost authentic."

Participant 12: "I can say that it was effective to know that there were others to communicate with."

Thanks to the avatars, the participants felt that they were communicating with real individuals. The participants reported that the avatars enabled them to feel as if they had been working side by side with others in the MUVE even though they were physically in different environments:

Participant 3: "Although we were not side by side, they made us feel as if we were together in the virtual environment."

\section{Meeting Rooms}

The participants reported that they were motivated and saved time by the existence of specific meeting rooms for the different groups:

Participant 8: "It motivated us and increased the level of seriousness in the meetings."

Participant 4: "The fact that there was a specific room for us let us know where we would meet when we logged in to the environment, so we did not waste time."

\section{The Effect on Social Presence}

The participants reported that the meetings were able to create the feeling of togetherness except when there were technical problems:

Participant 7: "When we spoke to each other, it was like normal communication."

Participant 5: "It made us feel as if we were together."

They also reported that the avatars had a positive effect on social presence. The avatars helped them to have a sense of belonging to the environment. The participants also emphasized the importance of having somebody to communicate with in the environment:

Participant 7: "Thanks to the environment, we could see one another."

Most participants stressed that having a meeting room exclusive to their group had a positive effect on social presence:

Participant 10: "By meeting with all the members of the group in the meeting room, we were able to communicate easily with virtual representations of each other."

In addition, having a specific meeting room for each group created togetherness and enabled the participants to have a sense of belonging to the environment:

Participant 10: "It ensured togetherness and helped us to have a sense of belonging to the environment."

Participant 5: "It made us feel as if we were together there."

Some participants reported that their photographs in the MUVE enabled them not only to have a sense of belonging to the environment and their groups but also to meet in 
the correct location when they first logged in to the environment:

Participant 6: "The photographs indicated that the environment was ours."

Participant 4: "With the photographs, I felt that I belonged to the group."

Participant 1: "They helped me to understand that I was in the correct location when I first logged in to the environment."

\section{Design Recommendations}

To increase the authenticity of the meetings, the participants recommended that meetings be held outdoors and that the environment have office equipment such as desks and chairs:

Participant 10: "Since it was an outdoor environment, it would have been better if additional equipment such as desks had been integrated."

In addition, the participants reported that the authenticity of the meetings could be increased by equipping the avatars with additional features such as the function of sitting on a chair.

\section{Advantages}

Thanks to the MUVE, communication contributed to the project processes. One advantage of the MUVE was the opportunity to discuss and share things. Participants mentioned that they could exchange their ideas by the help of MUVE:

Participant 6: "We discussed content design. We learned what the other members were doing."

Participant 8: "We used it to inform each other and generally to exchange ideas."

Participant 6: "We were able to express our ideas simultaneously, and everybody could hear them, which ensured instant communication."

Another advantage of the MUVE was saving time:

Participant 6: "Before we used this environment, we had many time-related problems, and we could not meet often."

Most of the participants reported that the MUVE made it easier for them to meet:

Participant 9: "Since many of us were able to join, it made it easier for us to meet when we could not meet physically."

Participant 12: "It enabled us to meet more often."

Since the MUVE was easily accessible from anywhere with a computer and Internet connection, the group members were able to participate in the project meetings no matter where they were physically located. During the interviews, the participants described it as another advantage of the MUVE to be able to meet by connecting at their home, dormitory, or other places especially when they could not meet physically:

Participant 5: "When we could not meet in the classroom or outdoors, we were able to meet in the MUVE by connecting from anywhere."

Also, the participants said that the MUVE helped ensure collaboration among the students while they were working on their projects:

Participant 5: "We found videos for the project. At the same time, we talked about how the design should be."

\section{Technical Problems}

Most of the problems with the use of the environment were technical. The participants' experience was hindered, in particular, by the inability to use voice communication regularly and effectively, problems with logging in to the software, and difficulty staying connected to it. Initially, there were too many users in the environment at the same time, which negatively affected the process. Then, the groups began to use the environment at different times. This helped overcome some of the problems, but the environment was still not trouble-free. The participants emphasized some of these problems:

Participant 9: "There were frequent disconnections, and we were simply unable to overcome the problems with voice communication."

Participant 11: "It would be better if access were denied when there were already 10 logins. Without this, crosstalk was inevitable."

\section{Limitations}

According to the participants, one of the limitations was the fact that the MUVE did not allow files to be shared. They also noted that they could not see what the other members of the group were doing, and they needed an additional instrument to do so:

Participant 6: "One could not see what the others were doing."

Participant 5: "In one way or another, we should have been able to see what we were doing and what outcomes we had. I do not think it was very effective in this respect."

The inability to share files in the MUVE affected collaborative learning among the group members:

Participant 7: "To ensure collaboration, there must be a common folder in that environment. Your work should be filed in an environment. To do so, we need a folder such as Dropbox to put our common folders in. When we met in this environment, we needed to use Dropbox more effectively."

Participant 12: "It might have been better if there had been a system for sharing folders."

To overcome this limitation, one participant proposed:

Participant 12: "We could have opened files in the integrated web browser and thus presented and shared our files there."

\section{Usability}

The usability of a virtual environment is determined by how necessary instructions are, how easily people can find what they are looking for and how well they can interact with the interface. The evaluation of these factors provides clues as to the usability of the environment. In this study, the participants did not have much trouble with the usability of the virtual environment since they were already familiar with computers:

Participant 5: "It was not that difficult to use the environment. It was like a game, so I did not have much difficulty."

Participant 6: "I did not need any instructions."

One negative feedback on usability was that it was difficult for some participants to figure out how to customize their avatars:

Participant 5: "We tried to figure out how to customize our avatars, but without success." 


\section{The Effect on Collaborative Work}

The effect of project work in the virtual environment on collaboration was analyzed by examining the extent to which the participants were able to use the features of the environment. Although voice communication was not highly successful because of the technical problems, the participants were able to exchange ideas by means of written communication. They were able to discuss the topics specified in the meetings and share files using additional devices such as Dropbox, which suggested that they were involved in basic collaboration. Here is some positive feedback on this issue:

Participant 5: "It was good because we were able to share our ideas."

Participant 7: "We exchanged ideas about the project design and conferred with one another about what to do to find the content."

Even so, one participant reported that there was no effective control over the participants, which negatively influenced collaboration:

Participant 6: "It was only enough in terms of exchanging ideas, but you could not see what they were doing."

Due to the technical problems with voice communication, most communication in the virtual environment was written, which the participants thought made the environment no significantly better than other similar platforms or devices:

Participant 11: "Well, we were able to communicate, but we can already meet our communication needs with other platforms such as Facebook."

Participant 9: "In terms of communication and other factors, it was not much different from environments used for written communication."

Nevertheless, the photographs aided communication during the sessions when voice communication was possible:

Participant 5: "The photographs were helpful since we could both hear and see the others."

According to the participants, the MUVE contributed to collaborative learning in terms of exchanging ideas during the project design and implementation:

Participant 4: "It helped us to see where we were in the project and what we should do."

Participant 7: "We exchanged ideas about the project design and conferred with one another about what to do to find the content. In this way, I realized what I was dealing with and what I was doing."

Another participant reported that the MUVE did not help much with the project, and that it can only be used for exchanging ideas in certain courses:

Participant 2: "I do not think the environment contributed anything to the project at all. I think the environment can be used by students who cannot meet regularly for non-math courses, which call for more discussion. It is a good environment for exchanging ideas."

In addition, the MUVE made the project meetings easier to schedule and attend. The participants reported that the MUVE enabled the group members to meet and collaborate:

Participant 10: "It made it easier for us to collaborate and meet even though we were in different locations."
Participant 7: "When we could not meet face-to-face during the day, we were able to meet in the virtual environment and hold at least one group meeting."

Participant 4: "We could not meet physically. I was far away, and some of our friends had other classes to attend. It was useful for meeting, although I did not participate much."

One participant said that the virtual environment was less effective since it did not allow real-time display of work synchronized with the discussions:

Participant 5: "In one way or another, however, we should have been able to see what we were doing and what outcomes we had. I do not think it was very effective since we could not see the outcomes."

\section{The Advantages of Using Dropbox}

One of the problems experienced by the participants was associated with sharing files. Working from different locations, the participants needed a way to share files. To meet this need, they used Dropbox. The data showed that the use of Dropbox for the project processes was useful for sharing and transferring information:

Participant 5: "In fact, it was good to have Dropbox since we needed to share many files as part of the project. Without Dropbox, we could not have exchanged these files since we were not side by side all the time."

Participant 1: "It helped a lot to share and transfer files."

Participant 11: "Dropbox enables you to share things and follow what we are doing."

Also, some participants reported that Dropbox made the project go faster:

Participant 7: "It made our work during the meetings proceed in an easy way."

Some participants stressed that Dropbox made it easier to follow work on the project. By sharing files with Dropbox, they were able to track quickly what the group members were doing:

Participant 11: "It was effective because it allowed us to track changes quickly."

The participants were able to follow their work by using Dropbox to access the files regardless of their locations:

Participant 12: "It helped us to follow what we were doing regardless of our locations."

In addition, Dropbox enabled them to carry out their project work in collaboration:

Participant 6: "I was able to revise the changes made by my friends."

The interviews revealed that another advantage of using Dropbox was related to time. The participants reported that they saved time by sharing files and keeping track of their work with Dropbox:

Participant 3: "It enabled what we were doing to be instantly transferred to others."

Participant 12: "We achieved instant sharing."

Participant 6: "Previously, we had to wait a day before our friends could see what we were doing."

Dropbox facilitated instant sharing and helped a lot since the participants developed many animation files as part of 
the project, and files with an ".exe" extension could not be sent by e-mail:

Participant 4: "It enabled us to see the contents of the animations instantly."

\section{The Advantages of Using Dropbox and the MUVE Together}

Dropbox was used to compensate for the inability to share files in the MUVE. In this way, the participants were able to make simultaneous amendments to the files and discuss a shared file as if they were communicating face-to-face. These were the positive effects of using Dropbox and the MUVE together. Here is how one participant described the way these two environments complemented each other: Participant 11: "It was very useful. Without Dropbox, it was difficult to transfer files in the MUVE. In addition, since our activities were mostly visual, it took a long time to transfer them over the Internet. It was even impossible on some occasions. Using Dropbox in the MUVE enabled our project work to be completed smoothly."

\section{Discussion}

MUVEs are reported to be promising environments to support collaboration and communication (Schultze \& Orlikowski, 2010). While the participants were carrying out collaborative learning activities in the MUVE, they felt as if they were working in an authentic environment. This was because they used their own avatars and their meeting rooms included their own photographs. In addition, the avatars and the meeting rooms created a feeling of togetherness. Avatars provide participants to engage in rich interactions that realizing the existence of the other team members in the environment. Avatars increases the sense of being with others by allowing participants to exchange ideas. Also, both avatars and design of meeting rooms provide authenticity by letting participants to navigate through the 3D world of MUVE (Bosch-Sijtsema \& Haapamaki, 2014; Davis et al., 2009; Messinger et al., 2009; Tüzün, Alsancak-Sırakaya, Altıntaş-Tekin, Yaşar-Eren, 2016; Zhao, 2003). The MUVE also overcame the problem of meeting as a group. The participants reported that the MUVE provided them with the convenience of logging in to the meetings wherever they were.

One advantage of the collaborative learning experience in the MUVE was voice communication. It helped the participants to express their ideas and listen to the ideas of their group members. Through written and voice communication, the participants were able to discuss their project work in the MUVE. However, voice communication could not be used effectively, and the participants mostly used written communication. This was because of both connection problems and technical problems caused by the system. It has been reported that written communication environments are not as effective as voice and video communication in giving individuals the feeling of social presence. This is because the number of words per second in written communication is much lower than that of speech. When individuals only use written communication, there will be less discussion, which has a negative influence on decision-making processes (Sallnas, 2005). Therefore, project meetings in MUVEs must have voice or video communication for students to have a good experience.

Although the collaborative experience in the MUVE was generally useful, the meetings in the environment did not fully meet the expectations of the students. This was probably because there were disconnections and technical problems with logging in to and using the environment. In addition, the location from which the participants accessed the meetings in the MUVE affected their attend- ance and desire to participate. This is because different locations have different Internet speeds and bandwidths, which may affect the quality of connection to the MUVE. As a result, there were low attendance figures in some of the groups. A large majority of the participants $(80 \%)$ considered face-to-face experience to be better than the MUVE experience for collaborative work on a group project. This was due to two main reasons. First, face-to-face communication is by nature more effective for interaction and sharing. Second, technical problems had a negative influence on the participants' performance in the MUVE. In face-to-face collaboration environments, participants can collaborate simultaneously since they are working around a table so there is a high level of understanding for shared activities. On the other hand, in technology mediated collaboration there might be low level of awareness for collaborators due to the missing visual cues (Poppe et al., 2017). Thus, technical problems that avoid effective communication among collaborators must be prevented in MUVEs to minimize the negative factors of distant collaboration in an online environment.

One limitation of the MUVE was that it did not offer a repository for sharing files. The participants needed to share their work instantly with their group members during the group meetings. Therefore, MUVEs should be integrated with file sharing environments. In this way, project work can be stored and shared in a common location. In addition, the opportunity to share and access project files from anywhere will enable group members to collaborate more quickly. Also, large-size files such as animation files can be shared with the group members. In this way, they will not have to meet physically to discuss the design of their projects, which, in turn, will enable them to save time.

In conclusion, project group meetings in MUVEs enable group members to exchange ideas and discuss through written and voice communication, creating a collaborative environment. These environments can be integrated with a file sharing platform so that group members can share files in an easier and faster way and thus enhance the effectiveness of their work. Since MUVEs cannot ensure satisfactory collaboration on their own, this integrated file sharing platform will enable project group members to work on project files simultaneously and exchange ideas regardless of time or location.

\section{Conclusion and Implications for Future Research}

In this study, the participants held project group meetings in the MUVE, where they were represented by avatars. They used both written and voice communication. As a complement to the environment, the participants used a file sharing platform, where project files were shared, followed and stored. Similar environments have been used in the literature for group work. These studies focus on social presence. Future research could use integrated MUVEs that involve voice, written, and video communication and allow file-sharing and whiteboarding. This can provide a synchronized virtual environment for users, and its effects on collaboration and social presence could be investigated. Future research could also study how these environments are used in software projects or social areas and thus identify how well they address a variety of needs.

\section{References}

Annetta, L. \& Park, J. C. (2006). Video games in science: A model for students and teachers creating 3D role playing games. Paper presented at the Annual Conference of the Society for Information Technology and Teacher Education, Orlando, FL. 
Blas, N. D., Bucciero, A., Mainetti, L., \& Paolini, P. (2012). Multi-User virtual environments for learning: Experience and Technology Design. IEEE Transactions on Learning Technologies, 5(4), 349-365. Retrieved from https://ieeexplore.ieee.org/stamp/stamp. jsp?tp $=\&$ arnumber $=6243131$

Bosch-Sijtsema, P.M., \& Haapamaki, J. (2014). Perceived enablers of 3D virtual environments for virtual team learning and innovation. Computers in $\mathrm{Hu}$ man Behavior, 37, 395-401. Retrieved from https://www.sciencedirect.com/science/article/pii/ S0747563214002465

Bruckman, A. (1996). Finding one's own space in cyberspace. Technology Review, 99(1), 48-54.

Bruckman, A. (2000). Uneven achievement in a constructivist learning environment. Paper presented at the International Conference on Learning Sciences, Ann Arbor, MI.

Chellali, A., Milleville-Pennel, I., \& Dumas, C. (2013). Influence of contextual objects on spatial interactions and viewpoints sharing in virtual environments. Virtual Reality, 17, 1-15.

Clarke, J., Dede, C., Ketelhut, D. J., \& Nelson, B. (2006). A design-based research strategy to promote scalability for educational innovations. Educational Technology, 46(3), 27-36. Retrieved from https:// pdfs.semanticscholar.org/6a8a/7e58f651 bbe02d9363a3cb6c890e0261996f.pdf

Cobb, S., Neale, H., Crosier, J., \& Wilson, J. R. (2002). Development and evalution of virtual learning environments. In K.M. Stanney (Ed.), Handbook of Virtual Environments: Design, Implementation, and Applications. Mahwah, NJ: Erlbaum.

Corbit, M. (2002). Building virtual worlds for informal science learning (SciCentr and SciFair) in the Active Worlds Educational Universe (AWEDU). Presence: Teleoperators \& Virtual Environment, 11(1), 55-67.

Davis, A., Murphy, J., Owens, D., Khazanchi, D., \& Zigurs, I. (2009). Avatars, people, and virtual environments: Foundations for research in metaverses. Journal of the Association of Information Systems, 10(2), 90117.

Denzin, N.K. (1970). The research act in sociology. Chicago: Aldine.

Denzin, N.K. (1978). Sociological methods. New York: McGraw-Hill.

Dickey, M. D. (2000). 3D virtual worlds and learning: An analysis of the impact of design affordances and limitations in Active Worlds, blaxxun interactive, and Onlive! Traveler: and a study of the implementation of Active Worlds for formal and informal education. Columbus, $\mathrm{OH}$ : The Ohio State University.

Dickey, M. D. (2003). Teaching in 3D: Pedagogical affordances and constraints of 3D virtual worlds for synchronous distance learning. Distance Education, 24(1), 105-121.

Doğan, D., Çınar, M., \& Tüzün, H. (2018). Multi-user virtual environments for education. In: N. Lee (Ed.) Encyclopedia of Computer Graphics and Games. Springer International Publishing. Doi: 10.1007/978-3-319. 08234-9_172-1. Retrieved from http://yunus.hacettepe.edu.tr/ htuzun/html/academic/2018-Dogan-Cinar-Tuzun.pdf
Edirisingha, P., Nie, M., Pluciennik, M., \& Young, R. (2009). Socialisation for learning at a distance in a 3-D multi-user virtual environment. British Journal of Educational Technology, 40(3), 458-479.

EDU-CAUSE (2007). The Horizon Report 2007 Edition, Austin, Tx: The New Media Consortium and Boulder, Co: Educause Learning Initiative. Retrieved from http:// www.nmc.org/pdf/2007_Horizon_Report.pdf

Gunawardena, C. N. \& Zittle, F. (1997). Social presence as a predictor of satisfaction within a computer mediated conferencing environment. American Journal of Distance Education, 11(3), 8-26.

Hämäläinen, R., Manninen, T., Järvelä, S., \& Häkkinen, P. (2006). Learning to collaborate: Designing collaboration in a 3-D game environment. Internet and Higher Education, 9, 47-61.

Ibanez, M.B., Rueda, J.J.G., Maroto, D., \& Kloos, C.D. (2013). Collaborative learning in multi-user virtual environments. Journal of Network and Computer Applications, 36, 1566-1576.

Leh, A.S. (2001). Computer-mediated communication and social presence in a distance learning environment. International Journal of Educational Telecommunications, 7(2), 109-128.

McCreery, M.P., Schrader, P.G., Krach, S.K., \& Boone, R. (2013). A sense of self: The role of presence in virtual environments. Computers in Human Behavior, 29(4), 1635-1640.

Messinger, P.R., Stroulia, E., Lyons, K., Bone, M., Niu, R.H., Smirnov, K., \& Perelgut, S. (2009). Virtual worlds past, present and future: New directions in social computing. Decision Support Systems, 47, 204-228.

Nelson, B., Ketelhut, D. J., Clarke, J., Bowman, C., \& Dede, C. (2005). Design-based research strategies for developing a scientific inquiry curriculum in a multi-user virtual environment. Educational Technology, $45(1), 21-34$.

Patton, M.Q. (1999). Enhancing the quality and credibility of qualitative analysis. HSR: Health Services Research, 34(5), 1189-1208.

Poole, D.M. (2000). Student participation in a discussion-oriented online course: a case study. Journal of Research on Computing in Education, 33(2), 162-177.

Poppe, E., Brown, R., Recker, J., Johnson, D., \& Vanderfeesten, I. (2017). Design and evaluation of virtual environments mechanisms to support remote collaboration on complex process diagrams. Information Systems, 66, 59-81.

Rice, R. E. (1992). Task analysability, use of new media, and effectiveness: amulti-site exploration of media richness. Organisation Science, 3, 475-500.

Rourke, L., Andersın, T., Garrison, D.R., \& Archer, W. (2001). Methodological issues in the content analysis of computer conference transcripts. International Journal of Artificial Intelligence in Education, 12, 8-22.

Sallnas, E.-L., (2005). Effects of communication mode on social presence, virtual presence, and performance in collaborative virtual environments. Presence, 14(3), 434-449. 
Salmon, G. (2004). E-moderating: the key to teaching and learning online (2nd ed.). London: Routledge Falmer.

Schultze, U., \& Orlikowski, W.J. (2010). Research commentary-virtual worlds: a performative perspective on globally distributed, immersive work. Information Systems Research, 21, 810-821.

So, H. J. \& Brush, T. A. (2008). Student perceptions of collaborative learning, social presence and satisfaction in a blended learning environment: Relationships and critical factors. Computers and Education, 51, 318-336.

Swan, K. (2003). Developing social presence in online discussions. In S. Naidu (Ed.), Learning and teaching with technology: principles and practices (pp. 147164). London: Kogan Page.

Tüzün, H., Alsancak-Sırakaya, D., Altıntaş-Tekin, A., \& Yaşar-Eren, S. (2016). Üç-boyutlu çok-kullanıcılı sanal ortamlarda buradalığın incelenmesi (An investigation of presence in three-dimensional multi-user virtual environments). Hacettepe Üniversitesi Ĕgitim Fakültesi Dergisi, 31(3), 475-490. Retrieved from http://yunus.hacettepe.edu.tr/ htuzun/html/academic/2016-Tuzun-AlsancakSirakaya-Presence. pdf

Zhao, S. (2003). Toward a taxonomoy of Copresence. Presence, 12(5), 445-455. 